See Article page 372.

\section{Commentary: The "girdle" Ross procedure: An adjunct to prevent late autograft failure in all Ross patients?}

\author{
Charles Laurin, MD, and François Dagenais, MD
}

The Ross procedure offers an excellent alternative to an aortic prosthesis in young patients with aortic valve stenosis. Published 20-year outcomes have established the safety and the superiority of the pulmonary autograft compared with conventional prosthesis in this setting. Whether to perform a Ross procedure in aortic insufficiency with annular dilatation is debated, owing to an increased late autograft failure by dilatation. Starnes and colleagues ${ }^{1}$ describe a modification of the full root replacement technique where the pulmonary autograft is reinforced with an external Dacron conduit. The rationale behind this modification is to support and stabilize the autograft, hence preventing late dilatation.

The authors are to be congratulated for the excellent mid-term results with a very low late failure rate and excellent long-term survival. As published by others, the surgeon's Ross learning curve has a clear effect on late outcomes. Better outcomes of the Ross procedure are reported after 75 to 100 cases/surgeon. ${ }^{2}$ In the present cohort of 129 patients, the unwrapped technique (71 patients) was performed in the early stage of the center's experience. Only $18 \%$ of the wrapped cohort was followed for 10 years, and $48 \%$ have 5 years of follow-up. Data presented are more representative of the early- to mid-term

\footnotetext{
From the Department of Cardiac Surgery, Institut Universitaire de Cardiologie et de Pneumologie de Québec, Université Laval, Québec, Québec, Canada.

Disclosures: Dr Dagenais is consultant and proctor for Cook Medical, Edwards Lifesciences, and Medtronic Inc. Dr Laurin reported no conflicts of interest.

The Journal policy requires editors and reviewers to disclose conflicts of interest and to decline handling or reviewing manuscripts for which they may have a conflict of interest. The editors and reviewers of this article have no conflicts of interest.

Received for publication Aug 11, 2021; revisions received Aug 11, 2021; accepted for publication Aug 13, 2021; available ahead of print Aug 20, 2021

Address for reprints: François Dagenais, MD, Institut Universitaire de Cardiologie et de Pneumologie de Québec, 2725 Chemin Sainte-Foy, Québec, Québec G1V 4G5, Canada (E-mail: francois.dagenais@chg.ulaval.ca).

JTCVS Techniques 2021;10:381-2

2666-2507

Copyright (C) 2021 The Authors. Published by Elsevier Inc. on behalf of The American Association for Thoracic Surgery. This is an open access article under the CC BY-NCND license (http://creativecommons.org/licenses/by-nc-nd/4.0/).

https://doi.org/10.1016/j.xjtc.2021.08.024
}

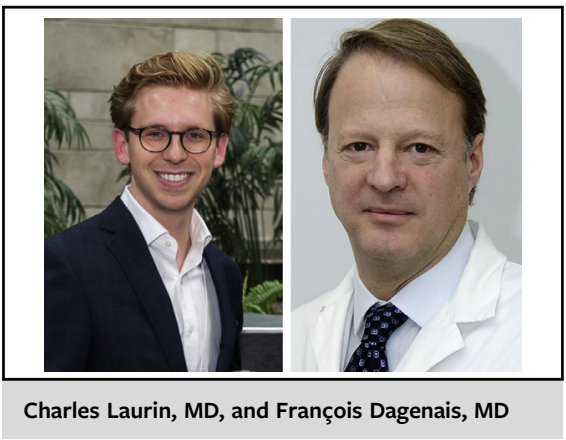

CENTRAL MESSAGE

The external reinforced Dacron conduit is a promising adjunct to prevent late autograft dilatation especially suited for patients with annular dilatation.

outcomes after the wrapped technique and thus mandate longer follow-up to assess true benefits on late reintervention.

Potential autograft dilatation may occur at the annulus level, the pulmonary sinus, and the new sinotubular junction. Aortic regurgitation and annular dilatation are associated with a greater risk of reintervention. Autograft dilatation is reported to potentially begin before hospital discharge, stressing the importance of the surgical technique. ${ }^{3}$ In the context of aortic regurgitation, implanting the autograft below the annulus, performing an external annuloplasty with a rim of Dacron, or adding a short interposition graft to stabilize the sinotubular junction are all techniques described, tailored to prevent dilatation of the autograft while minimizing deformation of the autograft and preserving the hemodynamic characteristics of the living autograft. ${ }^{4}$ Encasing the autograft in a Dacron tube lessens the systolic-diastolic motion of the pulmonary root, a mechanism known to contribute to the longterm durability of the pulmonary valve. In addition, the restriction on the sinuses imposed by the Dacron graft may affect the opening of the cusps and the coronary flow reserve.

As mentioned by the authors, the surgeon must be very careful in preventing distortion of the autograft while sewing the tube to the autograft, which could lead to an unfortunate early valve failure. Using a meticulous and reproducible technique, the authors show promising results, but there is an unequivocal need for long-term results. 
The inclusion technique should be part of the armamentarium of the surgeon performing Ross procedures and may increase the range of eligible patients to include patients with aortic annular dilatation. However, with the current knowledge, this surgical approach should be tailored to the patient's anatomy rather than applying the "girdle" effect to all Ross procedures. Until longer follow-up is available, we believe that external support of the autograft should be limited to patients at high risk of late autograft failure, mainly patients with aortic annular dilatation.

\section{References}

1. Starnes VA, Bowdish ME, Cohen RG, Baker CJ, Elsayed RS. The Ross procedure utilizing the pulmonary autograft inclusion technique in adults. J Thorac Cardiovasc Surg Tech. 2021;10:372-6.

2. Bouhout I, Ghoneim A, Poirier N, Cartier R, Demers P, Perrault LP, et al. Impact of the learning curve on early outcomes following the Ross procedure. Can J Cardiol. 2017:33:493-500.

3. Hokken RB, Takkenberg JJ, van Herwerden LA, Roelandt JR, Bogers AJ. Excessive pulmonary autograft dilatation causes important aortic regurgitation. Heart. 2003;89:933-4.

4. Bouhout I, Ghoneim A, Tousch M, Stevens LM, Semplonius T, Tarabzoni M, et al. Impact of a tailored surgical approach on autograft root dimensions in patients undergoing the Ross procedure for aortic regurgitation. Eur J Cardiothorac Surg. 2019;56:959-67. 